Faculty of Business

Faculty Publications

"Entrepreneurial imagining: How a small team of arts entrepreneurs created the world's largest traveling carillon"

Sara R. S. T. A. Elias, Todd H. Chiles, and Brett Crawford

2021

(C) 2021 Elias et al. This is an open access article distributed under the terms of the Creative Commons Attribution License. https://creativecommons.org/licenses/by-nc/4.0/

This article was originally published at:

https://doi.org/10.1177/01708406211035501

Citation for this paper:

Elias, S. R. S. T. A., Chiles, T. H., \& Crawford, B. (2021). Entrepreneurial imagining: How a small team of arts entrepreneurs created the world's largest traveling carillon. Organization Studies, 00(0), 1-24. https://doi.org/10.1177/01708406211035501 


\title{
Entrepreneurial imagining: How a small team of arts entrepreneurs created the world's largest traveling carillon
}

\author{
Sara R. S. T. A. Elias \\ University of Victoria, Canada
}

\section{Todd H. Chiles}

University of Missouri, USA

\section{Brett Crawford (iD}

Grand Valley State University, USA

\begin{abstract}
Although imagination has been recognized as essential to entrepreneuring, the processes by which entrepreneurs imagine and generate novelty remain insufficiently understood. To begin addressing this oversight, we propose a rhizomatic process model of entrepreneurial imagining that comprises five elements: experiencing, early creating, reaching an impasse and gestating, (re)creating and evaluating imagined futures, and choosing and enterprising. To generate this dynamic process model, we undertook an abductive, 25-month case study, guided by enactive research, to investigate how a small team of arts entrepreneurs created the world's largest traveling carillon. Our primary contribution is to offer new theoretical insights into entrepreneurial imagining as a complex, situated, relational performance that unfolds through conscious and unconscious, self-reflective and embodied processes.
\end{abstract}

\section{Keywords}

arts entrepreneurs, enactive research, entrepreneuring, imagining, organizing, rhizome

Imagination is critical for entrepreneuring the future. This claim is not new; economists George Shackle and Ludwig Lachmann emphasized imagination as a critical driver of entrepreneurial

\section{Corresponding author:}

Sara R. S. T. A. Elias, Peter B. Gustavson School of Business, University of Victoria, P.O. Box I700 STN CSC, Victoria, BC V8W 2Y2, Canada.

Email: selias@uvic.ca 
action several decades ago (Chiles, Vultee, Gupta, Greening, \& Tuggle, 2010a). Specifically, Shackle (1979) reflected on the connection between future-oriented imagination and entrepreneurial choice, which results in partly ex nihilo creation (i.e., origin of a new beginning, which flows from entrepreneurs' subjective expectations). Similarly, Lachmann (1986) suggested that by engaging forward-looking imagination, entrepreneurs continually generate novelty through a process of ex nihilo creation. Over the years, entrepreneurship scholars have also recognized the crucial role of imagining (e.g., Gartner, 2007; Hjorth, 2013), such as when Sarasvathy (2002, p. 95) encouraged entrepreneurship scholars to move imagination to 'center stage', or Chiles, Bluedorn, and Gupta (2007, p. 486) cited the need for closer attention to the 'central, but largely neglected' issue of 'the creation of opportunities through human imagination directed toward an envisioned future'. Yet little empirical effort has focused on entrepreneurial imagining (i.e., actively generating novelty through situated imaginative acts), and how it unfolds in already organized worlds.

That is, our understanding of this critical component of the entrepreneurial journey remains limited, as exemplified by the few existing process models of entrepreneurship that include imagination; those that do tend to be conceptual (e.g., Sarasvathy, 2001; Wood \& McKinley, 2010). Most models overlook imagination as a driver of entrepreneurial practices, despite their focus on facets of the entrepreneurial journey that inherently require imagination, such as design problem solving (Dimov, 2016) and bricolage (Baker \& Nelson, 2005). In turn, we lack insights into how entrepreneurial imagining unfolds over time, as part of the broader entrepreneurial journey, both shaping and being shaped by it. With this article, we propose a new model that features entrepreneurial imagining and explores the specific processes (conscious, unconscious, self-reflective, embodied) by which it unfolds. In addition to complementing extant models, our proposition is rooted in actual entrepreneurial practices, addressing Moroz and Hindle's (2012) critique of a general lack of empirical grounding for most models.

Integrating imagination into studies of the entrepreneurial journey also helps illuminate inventiveness and resilience in disrupting dominant, organized contexts. As Komporozos-Athanasiou and Fotaki (2015, p. 321) point out, 'imagination is "where it all begins", an inexhaustible psychosocial force driving organizations and organizing'. Inspired by radical processual philosophy, we accordingly view imagining as enabling, such that new worlds emerge from situated interactions, in continual processes of becoming and organizing (Hjorth, Holt, \& Steyaert, 2015). Entrepreneuring is a dynamic process, 'on the move', occurring not only as entrepreneurs start new ventures, but also in existing organizations (Hjorth, 2014, p. 108). By fostering links between entrepreneurship and organization studies, we hope to broaden the scope beyond a traditional focus on rationality, which overlooks the complexities of imagination, including desire and foolishness (Hjorth, 2014). This intersection of entrepreneurship and organization studies also represents a direct response to Lounsbury, Gehman, and Glynn's (2019, p. 1225) call for an interdisciplinary view in which entrepreneuring is not just a rational and economic outcome but a complex 'process of enterprising economic or non-economic activity'. Adopting multiple theoretical perspectives, we explore entrepreneurial imagining in the context of arts entrepreneuring, in which non-economic entrepreneurial activities often outweigh economic ones (Elias, Chiles, Duncan, \& Vultee, 2018).

In an attempt to understand the micro-foundations of entrepreneurial action (Dimov, 2011), we explore contextualized performances involved in entrepreneurial imagining, as experienced, thought, and felt by a small team of arts entrepreneurs who created the world's largest traveling carillon. We explore how they engage imagining to generate new possibilities for the future; despite economic precariousness, they exhibit resilience and disrupt well-instituted contexts through a process of actualizing imagined ideas (Parkkari \& Verduijn, 2019). This view acknowledges entrepreneuring and organizing in creative industries as unfolding processes that shape and are shaped by an existing social order (Louisgrand \& Islam, 2021). Furthermore, we take a radical processual 
approach (Hjorth et al., 2015) rooted in contextualism - a non-mechanistic worldview that highlights dynamism, relationality, interconnectedness, and novelty (Chiles et al., 2010a) - to tackle the difficult question of how entrepreneurs imagine and generate novelty in response to context (Hjorth, 2013). Specifically, how do entrepreneurs imagine new ideas, generate novelty, and make a difference in the future? To gain answers, we conduct a 25 -month case study, guided by enactive research (Johannisson, 2011), to abductively generate a dynamic process model of entrepreneurial imagining. With our radical processual approach, the goal is to provide insight into patterns, rather than establish a comprehensive law, of entrepreneurial imagining (Hjorth et al., 2015). Our philosophical position is ontologically relational and epistemologically constructionist.

We offer four contributions. First, we develop a process model of entrepreneurial imagining as a complex, situated, relational performance comprising five interrelated elements. Central to our model is the metaphor of the rhizome, a plant stem that grows horizontally, extending roots in different and unexpected directions; defining features are connectivity, continual change, and openendedness (Deleuze \& Guattari, 1987). This metaphor captures the situated, dynamic, and indeterminate character of imagining, which enables the emergence of multiple and heterogeneous worlds that are 'surprisingly novel at every turn' (Chia, 1999, p. 214). Second, a deeper understanding of how entrepreneurial imagining unfolds complements existing process models of the entrepreneurial journey, providing valuable insights into imagining as a key component of entrepreneurial processes, such as opportunity production (Wood \& McKinley, 2010), bricolage (Baker $\&$ Nelson, 2005), artefact creation (Selden \& Fletcher, 2015), and design problem solving (Dimov, 2016). Third, we contribute to nascent entrepreneurship research that features radical processual studies by providing empirical grounding of entrepreneuring as a process of 'disclosing that which is not yet fully known' (Hjorth et al., 2015, p. 600; Parkkari \& Verduijn, 2019), including entrepreneurial imagining. Fourth, we link organization studies and art by spotlighting arts entrepreneuring as a particularly fruitful context for exploring imagining as a powerful driver of new ways of entrepreneuring and organizing.

\section{Imagining and the Entrepreneurial Process}

As an essential human process that is both conscious and unconscious (Jung, 1997), imagining allows persons and organizations to change their current state of affairs (Diamond, 2014) and make a difference in the world (Hjorth, 2013). Yet imagining is not confined to the mind but rather constantly interacts with a wide range of bodily and social activities (Modell, 2006) that are critical for sparking perceptions, thoughts, and images in processes of novelty creation (Cornelissen, 2013) and organizing (Komporozos-Athanasiou \& Fotaki, 2015). Like a rhizome, imagining unfolds through perpetual motion and complete interconnectedness among heterogeneous constitutive elements (Deleuze \& Guattari, 1987). That is, we view imagining as an active, generative, embodied, situated activity that is deeply intertwined with perceiving and thinking (Thompson, 2018a): as an ability to integrate sensory experience, memory, and emotions, it facilitates perceiving and interpreting the world (Sartre, 1978); as an abstract cognitive activity, it sparks thinking and paves the way to creative outcomes (Arnheim, 2004). Extant entrepreneurship literature identifies critical roles of imagination, such as for creating new venture ideas (Cornelissen \& Clarke, 2010), devising resource combinations needed to actualize entrepreneurial ideas (Dolmans, van Burg, Reymen, \& Romme, 2014), and driving disequilibrium in market processes (Chiles et al., 2010a). As Thompson (2018b, p. 126) emphasizes though, entrepreneurship scholars rarely 'have undertaken the difficult task of theorizing upon the entrepreneurial imagination directly'. Kier and McMullen (2018, p. 2285) echo this point, encouraging researchers to conduct interpretive and processual studies to enhance 'understanding of the unconscious, embodied, and sensory nature of imagination'. 
If imagining is an open-ended, dynamic, ongoing process, its rhizomatic spread should enable people and organizations to extend beyond their present situations to generate novelty in the future (Hjorth, 2013). Imagining is at the root of human freedom: people are free to imagine unlimited alternatives to current states (Dyer, 2012; McGinn, 2006) and to initiate unexpected change (Chiles et al., 2010a). Because every person has a unique past and perception of the present, entrepreneurial choices to pursue some imagined future become the locus of partly (not wholly) ex nihilo creation (i.e., origin of a new beginning) (Shackle, 1979). Imagining unfolds in response to and is deeply entwined with contextual circumstances (Hjorth, 2013), so a myriad of futures may be imagined or abandoned. As a dynamic process in constant flux, entrepreneurial imagining may thus 'be broken, shattered at a given spot, but it will start up again on one of its old lines, or on new lines', branching out in line with a rhizomatic view (Deleuze \& Guattari, 1987, p. 9). Entrepreneurship literature traditionally has associated choice and imagination with early entrepreneurial stages (e.g., ideation, opportunity recognition), even though imagination is constant and always present in the flux of entrepreneurial (and organizational) life, not confined to any specific phase of an entrepreneurial process (Thompson, 2018b). Economists also explain that entrepreneurial innovation requires continual (re)organizing of resources, based on either entrepreneurial will (Schumpeter, 1939) or entrepreneurial imagination (Lachmann, 1986), which foreshadows Thompson's (2018b) arguments about the ongoing nature of imagination. Entrepreneuring thus transpires within an organized, ever-evolving world, in which imaginative entrepreneurs generate novelty and new beginnings in the midst of complexity and opportunity.

In a systematic review of 32 process models of entrepreneurship, Moroz and Hindle (2012) unpack four competing views: emergence, value creation, creative process, and opportunity discovery. They also identify some problems, including the fragmented nature of extant models and a lack of empirical grounding on actual entrepreneurial practices, leading them to lament the failure of existing models to accommodate different perspectives, such that users must 'adhere, a priori, to a limited or highly prescribed perspective of what entrepreneurship is' (Moroz \& Hindle, 2012, p. 810). These authors thus call for a 'comprehensive, evidence-based model of entrepreneurial process that is consistent with a strong theoretical and philosophical appreciation of process' (Moroz \& Hindle, 2012, p. 811). Hindle (2010) had previously attempted to harmonize major elements of competing models but without integrating imagination, which we regard as critical to two key elements, namely, evaluation of opportunities and commitment to creating value. We answer this call by unpacking imagination, grounding it in interdisciplinary insight and the experiences of actual entrepreneurs.

Our review of process models in entrepreneurship reinforces that a deeper understanding of imaginative processes might illuminate fundamental, under-theorized influences of imagining, as well as animate key aspects of the entrepreneurial journey. That is, an empirical exploration of imagining can benefit constructivist scholars interested in how opportunities emerge from entrepreneurs' actions (Dimov, 2011), such as Wood and McKinley's (2010) efforts to introduce a conceptual model of opportunity production in which entrepreneurs first conceptualize and objectify an opportunity, before ultimately enacting it into a new venture. Although they acknowledge the importance of imagination in this first stage, a deeper exploration might reveal how entrepreneurs imagine opportunities and experience sensemaking to establish whether the envisioned future is viable (Wood \& McKinley, 2010). Similarly, imagination can complement Baker and Nelson's (2005) model of entrepreneurial bricolage, by illuminating the imaginative processes that help entrepreneurs (re)combine 'resources at hand' as they 'create something from nothing'. As Selden and Fletcher (2015) recognize, foresight and imagination are important throughout the entrepreneurial journey, though they do not detail the imaginative processes driving this emergent, selforganized, and hierarchical system. Likewise, imagination can complement Dimov's (2016) 
three-category model of design problems, by providing insights into how entrepreneurs devise ways to connect with existing and imagined customers while generating novelty and sustaining entrepreneurial activities over time. Ongoing (inter)connectivity and iterative dialogue among various elements of the broader entrepreneurial journey are critical for imagining, which rhizomatically unfolds in unpredictable directions (Nicolini, 2009). We thus aim to add to existing process models that illuminate the entrepreneurial journey by also accounting for the rarely addressed concept of imagining.

\section{Research Approach}

We conducted a 25-month case study to investigate how a small team of arts entrepreneurs created the world's largest traveling carillon. This focus on arts entrepreneurs is relevant because this context is largely overlooked but also fruitful for exploring entrepreneurial dreams (Rindova, Barry, \& Ketchen, 2009) and entrepreneurial imagination (Hjorth, Strati, Drakopoulou Dodd, \& Weik, 2018). Arts entrepreneurs and artists also are trained to reflect on, bring into awareness, and verbalize the imaginative, often ineffable processes that undergird novelty generation (Elias et al., 2018). Finally, our first author, Sara, is a practicing arts entrepreneur, which provides access to a holistic exploration of entrepreneurial imagining in this context.

To deepen understanding of a highly subjective process that is neither directly observable nor easily verbalized, we adopt a constructionist epistemological positioning (Steyaert, 1997), grounded in 'knowing-from-within interactive moments' (Cunliffe \& Eriksen, 2011, p. 1433). Following Johannisson (2011), Sara fully immersed herself in the focal phenomena through enactive research, exploring entrepreneurial imagining in practice, while enacting it, as both researcher and situated actor, which helped make explicit its tacit and ineffable dimensions while incorporating multiple perspectives (Fletcher, 2011). Given Sara's position, and our abductive approach, we relied on introspection and reflexivity to alternate between data and extant literature (Alvesson \& Sköldberg, 2009); our second and third authors remained 'distant', providing collective reflexivity and, ultimately, theoretically generative insights. Using an instrumental case study (Stake, 1995), we focus on unique entrepreneurial performances to inform a view of something more general than the case itself (i.e., the processes by which entrepreneurial imagining unfolds over time).

The case is Associação CICO (International Centre for the Carillon and the Organ), a Portuguese arts venture co-founded by three arts entrepreneurs: (1) Ana Elias, the artistic director and a professional performing artist and teacher with expertise in engineering and pedagogy; (2) Sara Elias, the managing director and a professional performing artist and entrepreneurship scholar; and (3) Alberto Elias, the president and a mechanical engineer and teacher with expertise in computeraided design. Although not an artist, Alberto is an arts entrepreneur because he actively engages in entrepreneurial efforts to promote artistic work (Elias et al., 2018; Scherdin \& Zander, 2011) that drive market processes (Davidsson, 2004). Both Ana and Alberto have participated in many entrepreneurial projects, both with each other and with others. We included all these projects in data generation and analysis, but for clarity, the data presented refer solely to the LVSITANVS Carillon, Portugal's only traveling carillon and the world's largest (63 bells) and heaviest ( 7 tons of bronze). (Carillons, typically inside bell towers, comprise at least 23 cast bronze bells, tuned and mechanically activated through a manualboard and pedalboard; traveling carillons are transported by truck to play outdoors or indoors.) When this research started, Ana, Sara, and Alberto were imagining and working to actualize this project. 


\section{Data generation and analysis}

Consistent with abduction, we generated and analysed data while conducting field research simultaneously, in an 'iterative process of transposing our observations, participants' accounts and theory in relation to our research [question]', such that in our article we interweave theory with participants' comments (Cunliffe \& Eriksen, 2011, p. 1428). To begin, Sara wrote a reflexive narrative about her entrepreneurial experience, which indicated the critical role of imagining. In reviewing entrepreneurship theory, we noted the lack of in-depth insights into imagining. On the advice of a theoretically diverse panel of three senior organizational scholars, we selected seven books as a theoretical foundation for generating our model. These texts contain both canonical (Arnheim, 2004; Jung, 1997; Sartre, 1978; Shackle, 1979) and more recent (Dyer, 2012; McGinn, 2006; Modell, 2006) efforts to explore imagination; they span art/design, cognitive psychology, economics, evolutionary biology, linguistics, neurobiology, neuroscience, philosophy, psychoanalysis, and spirituality.

Following a case study method (Stake, 1995), field research entailed generating data through interviews, immersive fieldwork, reflexive fieldnotes, and secondary sources. At three points in time $\left(t_{o}, t_{12}, t_{24}\right)$, Sara conducted fieldwork in Portugal, each time for about three weeks. In a twophase interview process, she interviewed Ana and Alberto separately, starting with open-ended questions about each participant's experiences with creating entrepreneurial ventures (formation, evolution over time, dissolution), then proceeding to semi-structured questions focused specifically on imagining. Thus, she first engaged in phenomenological interviewing (Cope, 2005), taking a passive role and letting Ana and Alberto describe their lived experiences; she then took a more active role, engaging in conversation and negotiations of meaning about entrepreneurial imagining, an intersubjective approach that Brinkmann and Kvale (2015) describe as an 'interview'. To capture multiple entrepreneurial projects, undertaken by the organization and by Ana and Alberto individually, this two-phase interview process unfolded over two weeks. During this period, Sara also conducted immersive fieldwork, by helping to conduct ergonomic studies and industry research, design innovative features in the traveling carillon, and develop creative forms of sponsorship, all of which required imagining. Participating in these activities was crucial to experience imagining first-hand and understand its ineffable and tacit dimensions while conversing with participants about their experiences.

When she was not physically in Portugal, Sara interacted with Ana and Alberto via Skype, conducting follow-up interviews, both individually and collectively, and participating in co-founder meetings once or twice per week for several hours at a time. These conversations helped capture real-time processes (cf. retrospective reconstructions) as the organization experienced them (Johannisson, 2011) and as its founders endeavoured to complete the LVSITANVS Carillon project and start new ones. Data were generated for 25 months, to ensure we saw the project to completion. In addition to interviewing Ana and Alberto, Sara gathered accounts from various stakeholders, such as public officials, financial advisors, community members, students, artists, and sponsors. They provided contextualized views of the focal entrepreneurial efforts. Most interviews were audio- and videotaped (approximately 86 recorded hours) and transcribed using Transana video analysis software. Secondary data include 33 carillon-related books, eight unpublished dissertations/papers, informative booklets and specifications developed by the co-founders for various carillon projects, websites and video- and audio-recordings of existing carillons worldwide, media coverage of the co-founders' entrepreneurial practices over 18 years, and an extensive catalogue of photographs of carillons and their mechanisms gathered by the co-founders over 25 years.

We analysed data using Brinkmann and Kvale's (2015) bricolage approach, which emphasizes moving freely among data, analysis, and theory. Inspired by post-coding analysis (St. Pierre \& 
Jackson, 2014), this approach is emergent and experimental, unfolding like a rhizome that is 'open and connectable in all of its dimensions; it is detachable, reversible, susceptible to constant modification' (Deleuze \& Guattari, 1987, p. 12). Reading and writing provided the post-coding analysis, through which we made rhizomatic connections by highlighting and labelling significant data and theory segments (Augustine, 2014). We also wrote memos to track and develop emerging themes, based on their recurrence, repetition, and forcefulness (Owen, 1984). By iterating between reading transcripts, secondary data, and theory while writing reflexive fieldnotes and composite narratives, we made sense of data patterns in context (St. Pierre \& Jackson, 2014). Furthermore, we sketched processual diagrams to depict connections among themes (Brinkmann \& Kvale, 2015). Our research question and interpretive repertoire (Alvesson \& Sköldberg, 2009) guided our analysis but did not hinder the emergence of themes. In addition, we engaged an aesthetic mode of knowing (Creed, Taylor, \& Hudson, 2020), using sensory experience, contemplation, intuition, self-talk, imagination, and reflexive conversations to refine the diagrams continually into our process model. Moreover, we discussed the model's various iterations and key conceptual ideas with Ana and Alberto, who provided critical feedback. For example, they noted when early iterations inappropriately depicted imagining as linear or orderly, whereas their experience of it was dynamic, complex, and messy. Such feedback, which surprised us at times, was key to our reflexive consideration of modifications and ultimate recognition of the rhizomatic nature of entrepreneurial imagining.

\section{Entrepreneurial Imagining: A Rhizomatic Process Model}

Our process model (Figure 1) draws inspiration from Nicolini's (2009) use of rhizomes, a metaphor we adopt for depicting entrepreneurial imagining. As Deleuze and Guattari (1987, p. 7) explain, 'The rhizome itself assumes very diverse forms' and 'includes the best and the worst: potato and couchgrass, or the weed'. Similarly, entrepreneurial imagining, with its unpredictable and indeterminate character, lacks any well- or pre-defined shape and entails both triumphs and misadventures. From a rhizomatic perspective, entrepreneurial imagining 'has no beginning or end; it is always in the middle' (Deleuze \& Guattari, 1987, p. 25), perpetually unfolding in unexpected directions, in an infinite process of heterogeneous becomings (Chia, 1999), and constantly interacting with a parallel space of various bodily and social activities. We zoom in on imagining, depicting this dynamic, complex, situated process in a model and explaining its elements separately, though they interconnect continually and iteratively inform one another.

Although entrepreneurial imagining is unpredictable, certain elements inherently precede others (e.g., experiencing precedes early creating; choosing and enterprising results from an ideation process that starts with experiencing). Following McMullen and Dimov (2013), we represent this directionality through an amorphous arrow in Figure 1 to suggest how the entrepreneurial journey might unfold through entrepreneurial imagining (many variations are possible, even for the same person). Imagining is unique to each entrepreneur and context. Thus, the duration of each element varies, ranging from fleeting moments to prolonged periods. Because our model portrays imagining comprehensively, it includes elements that may be bypassed too. For example, reaching an impasse and gestating is not a necessary condition for entrepreneurial imagining (or for the unconscious to work), so as depicted in Figure 1, early creating may lead directly to (re)creating and evaluating imagined futures. Even if people abandon an idea without actualizing it, they still experience entrepreneurial imagining, because they actively engaged in situated imaginative acts. Next, we detail each element and key conceptual ideas, represented by small circles in Figure 1. 


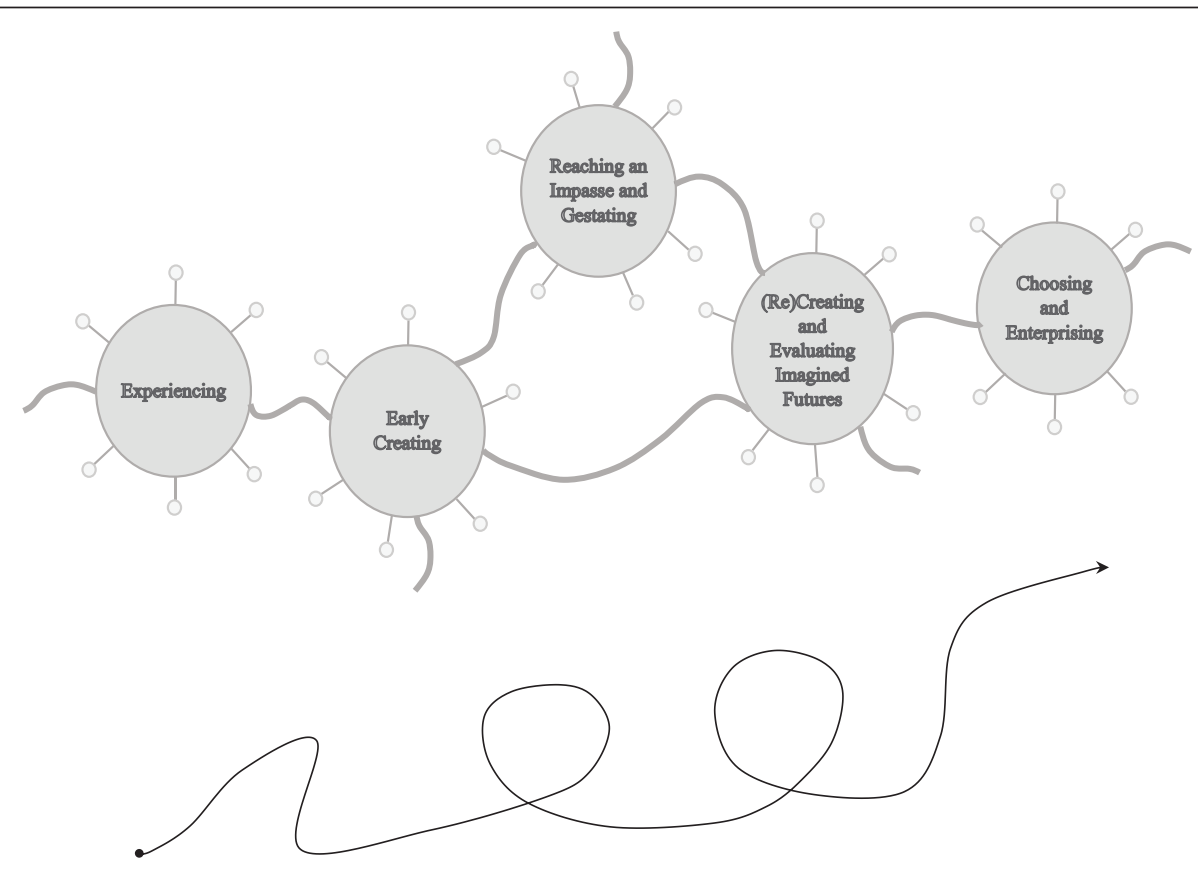

Key Conceptual Ideas Embodied in the Five Elements (represented by small circles in the model):

\begin{tabular}{|c|c|c|c|c|}
\hline Experiencing & Early creating & $\begin{array}{l}\text { Reaching an } \\
\text { impasse and } \\
\text { gestating }\end{array}$ & $\begin{array}{c}\text { (Re)creating and } \\
\text { evaluating imagined } \\
\text { futures }\end{array}$ & $\begin{array}{c}\text { Choosing and } \\
\text { enterprising }\end{array}$ \\
\hline $\begin{array}{l}\text { Perceiving } \\
\text { (external and } \\
\text { internal) } \\
\text { Thinking } \\
\text { Past experi- } \\
\text { ence, knowl- } \\
\text { edge, and } \\
\text { (unconscious) } \\
\text { memory } \\
\text { Attention } \\
\text { (objective and } \\
\text { subjective) }\end{array}$ & $\begin{array}{l}\text { - Imaginative } \\
\text { sensing (e.g., } \\
\text { seeing, hear- } \\
\text { ing, touch- } \\
\text { ing) } \\
\text { - Recom- } \\
\text { binatory } \\
\text { metaphoric } \\
\text { process }\end{array}$ & $\begin{array}{l}\text { - Unconscious } \\
\text { imagining } \\
\text { - Unconscious } \\
\text { recombinatory } \\
\text { metaphoric } \\
\text { process } \\
\text { - Conscious } \\
\text { intention } \\
\text { (developing and } \\
\text { suspending of) }\end{array}$ & $\begin{array}{l}\text { - Consciously process- } \\
\text { ing unconscious } \\
\text { material } \\
\text { - Considering epis- } \\
\text { temic possibilities } \\
\text { - Creating different } \\
\text { imagined futures } \\
\text { - Formulating neces- } \\
\text { sary courses of action } \\
\text { - Empathic imagining } \\
\text { - Embodied imagining }\end{array}$ & $\begin{array}{l}\text { - Emotional antici- } \\
\text { pation } \\
\text { - Committing to a } \\
\text { particular future } \\
\text { - Subjecting oneself } \\
\text { to loss and uncer- } \\
\text { tainty } \\
\text { - Passionately } \\
\text { believing } \\
\text { - Visualizing the } \\
\text { imagined future } \\
\text { - Acting as if }\end{array}$ \\
\hline
\end{tabular}

Figure I. A Rhizomatic Process Model of Entrepreneurial Imagining.

\section{Experiencing}

Entrepreneurial imagining is rooted in each entrepreneur's unique past and experience of the present. Entrepreneurs experience the surrounding world, disconnected from imagining into the future (McGinn, 2006), which constitutes an analytical disconnect. In practice, experiencing and imagining compose a rapid micro-process that commences with the human senses (Creed et al., 2020). Experiencing involves perceiving and thinking, which are often separated in analyses, but in practice, they also intertwine, resulting in a continual interaction between the gathering and the processing of information (Arnheim, 2004). Indeed, as entrepreneurs perceive the surrounding 


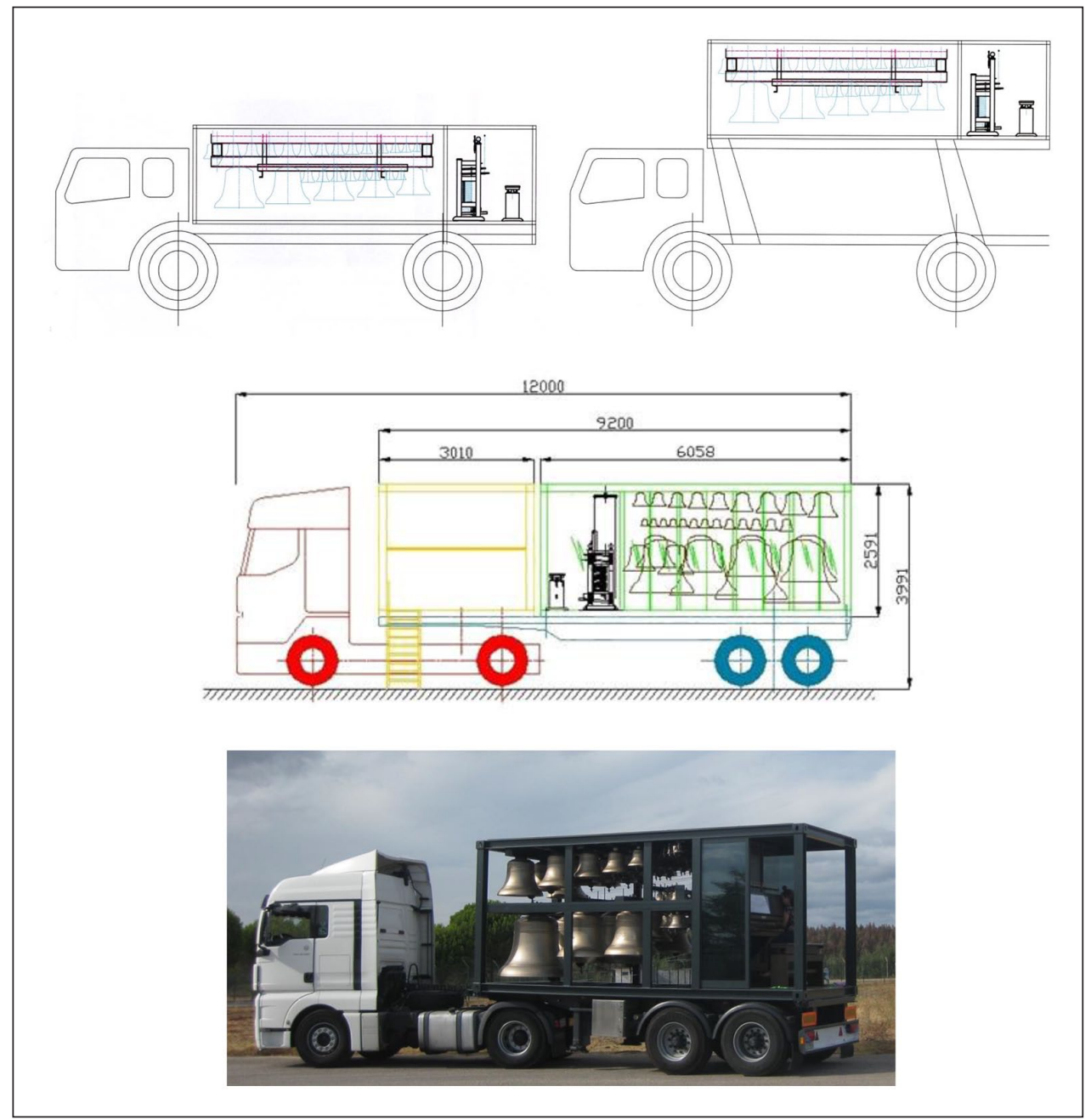

Figure 2. Visuals of the LVSITANVS Carillon, original version (upper left and right), revised version (middle), and actual (photo, lower). Please see online for the colour version of this figure.

world-which includes institutional and business environments (Crawford \& Dacin, 2020; Dolmans et al., 2014) - they are thinking. Their thoughts influence what they see, and what they see influences their thoughts. The rapid links across perception and thought allow entrepreneurs to interpret impressions from their surrounding world, resulting in what Shackle (1979) calls reports from the field. But perceiving does not entail solely a focus on the external world (or external perceiving), because entrepreneurs also gather information from their bodies (internal perceiving) (Modell, 2006), become aware of their affective reactions to the surrounding world, and project meaning onto it (Sartre, 1978).

The idea for the LVSITANVS Carillon, as Ana explained, first developed in 'Alberto's mind in 1998 when we saw a traveling carillon . . . in Belgium and [Ana and Sara] both performed for the first time in this instrument' (external perceiving). Figure 2 shows the structure of the LVSITANVS Carillon at different stages of development and a picture of the actual carillon. As Ana further elucidated, 
We interacted with the traveling carillon and we saw the possibilities of such instrument [external perceiving]: getting the carillon to the people instead of getting the people to the carillon. . . . So then you immediately start thinking how you can get one of these "toys" in Portugal [thinking].. . .I am very passionate about the carillon. . so this idea eventually became very exciting [internal perceiving]!

When explaining the source of this idea, Alberto clarified that his experiencing of a traveling carillon in Belgium allowed him to think of ways to pursue an untapped opportunity in Portugal:

I thought that the traveling carillon presented a solution [thinking] to the problem of people [in Portugal] not knowing what a carillon is [external perceiving]. I felt that there was a need [internal perceiving] to introduce our country to a new attitude toward music that otherwise people would not hear about; I thought we should pursue this opportunity [thinking]. . . [and] I enjoyed having this idea [internal perceiving].

Although the processes by which Alberto described feeling a need and thinking about pursuing the opportunity and Ana noted seeing its possibilities are similar to imagining into the future, it is important to re-emphasize that, in practice, imagining is deeply intertwined with (informs and is informed by) thinking and perceiving (external and internal) (McGinn, 2006). Therefore, experiencing, though analytically separate from imagining, is part of the overall process of entrepreneurial imagining.

People experience the world in the present, but they also store perceptions and thoughts that become part of their experience, knowledge, and memory. Thus, the continually changing past influences how they select, interpret, and supplement perceptions in the present (Arnheim, 2004), as well as the thoughts they formulate about those perceptions. Perceptions and thoughts stored in the mind become unconscious memory, waiting to be selectively activated. Memory is the ability to continually (re)categorize perceptions; unconscious memory comprises latent categories that may be retrieved and associated with immediate experiences as a person interacts with and interprets the world (Modell, 2006). As entrepreneurs experience the world, they recover and recontextualize specific memories, and this process enables them to recognize novelty as they notice similarities and differences among perceptions, external or internal (Modell, 2006).

The idea for a traveling carillon first came to Alberto in 1998, then went dormant as other projects took priority. However, as Ana explained, 'About six years later, [Alberto] found a call for proposals for innovative ideas developed by young Portuguese minds [external perceiving] and "Pling!" the idea came back to him [selectively activating unconscious memory].' The call cited design, multimedia, and music, but the prompt for innovative projects in Portugal immediately led us - that is, Sara in collaboration with Ana and Alberto - to think of a traveling carillon, reflecting our past experience and background (carillon art, entrepreneurship, engineering). Had our backgrounds derived from a different area of expertise, we might have come up with different ideas or noticed different reports from the field. Through further discussion, we recovered and recontextualized specific memories relating to carillon mechanics, performance, and ergonomics that when combined with thinking and perceiving, enabled us to recognize novel approaches to a traveling carillon.

Attention has a key role throughout the process of entrepreneurial imagining; while facilitating both perceiving and thinking, attention allows the mind to focus selectively on what is relevant while avoiding information overload (Arnheim, 2004). Dyer (2012) distinguishes two types of attention: objective (focusing on external information) and subjective (monitoring internal impressions). He proposes attending to the latter first and ignoring external impressions (external perceiving) that contradict internal thoughts and desires. Both Ana and Alberto recalled the varied feedback we received in response to explaining our intention to create an innovative instrument. Along with 
positive comments and encouragement, others reacted by saying, for example, 'What, are you crazy?!' 'Where will you find the money to buy such a pricy instrument?' and 'Yes, this is a great idea, but I doubt it that it will ever actually come true.' A retrospective assessment indicates that we did exactly as Dyer (2012) suggests: we purposefully disregarded negative external impressions (external perceiving), unless they were in some way constructive, and maintained subjectively focused attention. As Ana explained, regarding criticism, 'When people say that I'm talking crazy [about carillons], I smile and don't let it affect me [keeping attention subjectively focused]; instead, I try to think of ways to flip their perspective.' Although sometimes difficult, attending primarily to subjective impressions and thoughts had been key to the success of various carillon projects.

Noting the interplay between people's unique past and perceptions and thoughts in the present, Arnheim (2004) suggests the past is in the present. This notion is relevant to this element, during which entrepreneurs rapidly experience the world, disconnected from imagining. But as they start imagining the future, their creations are influenced by their past and present; arguably then, both past and future are in the present (Shackle, 1979). This interweaving, which reflects the rhizomatic nature of imagining, accentuates the temporal structure of experience as 'a fusion of heterogeneous instants, an indivisible flux and becoming' (Chia, 1999, p. 217) that is critical to the model's other elements.

\section{Early creating}

While early creating, entrepreneurs start imagining novelty into the future. Through imaginative sensing, they begin 'seeing-as' (or, in some cases, hearing-as), a process involving interactions of perceiving and imagining, and thus a collaboration between the body's and the mind's eye (McGinn, 2006). While seeing-as (or engaging in imaginative seeing), people distort a particular perception by imaginatively assigning different interpretations to it (McGinn, 2006). Aided by thought, they (re)combine elements, such as present and past perceptions, experiences, and knowledge, rearranging the world in their minds and envisioning different, unseen worlds through a recombinatory process facilitated by metaphor (Modell, 2006). Metaphor allows for the transference of insights among different, previously unconnected domains and also facilitates the transformation of meaning and generation of novelty (Cornelissen \& Clarke, 2010). Metaphor is not limited to language but rather is an embodied mental activity that 'transcends words' and 'provides connections' (Diamond, 2014, p. 105) through interactions with the world that facilitate new perceptions, thoughts, and images across dissimilar domains (e.g., past/present/future, cognitive/sensory/ world). This metaphoric process allows entrepreneurs to look at a specific product and start seeing it as a different, improved product, the same product serving a new function, or both. Not all recombinatory processes are metaphoric, but 'imagination could not exist without this recombinatory metaphoric process' (Modell, 2006, p. 27).

In the case study, we originally wanted to create a unique instrument with novel features, namely, a transposition system that would more easily enable the carillon to play with other instruments or quickly change key mid-concert (an idea we are still developing) and a mechanism that would let it be lifted up in the air so that, even if a larger crowd gathered, everyone could see the carillonist perform (Figure 2, upper left and right). We eventually realized that a transposition system would require more bells, increasing the instrument's projected weight to a level that would no longer allow lifting. We thus changed these original plans and decided to acquire a large, heavy instrument (too heavy to lift) that was aesthetically pleasing, both visually and sonorously (Figure 2 , middle). To refine this idea, we started looking at existing traveling carillons (external perceiving), studying their structure and (re)combining their characteristics (perceived in the present), while also activating, at times unintentionally, our past experience, knowledge, and memory to 
start seeing them as the future traveling carillon (recombinatory metaphoric process-past/present/future domains; imaginative seeing). Ana provides an illustrative account:

You look at one carillon [external perceiving] and you see the one mechanism that didn't work; you realize you don't want that [thinking; internal perceiving], but you grab the image of what worked and put it in a drawer. And the same thing for other carillons and drawers. My brain's like drawers in an armoire. I don't know what happens inside when you close the drawers [to store information] but then these papers with images get mixed up. . .and eventually you come up with a new idea [for the future carillon] [recombinatory metaphoric process - past/present/future domains].. . .You develop a new project and you start seeing things [imaginative seeing]. If you ask me to draw it, I can't, because the image in my mind isn't defined yet. ...Then, you start thinking about the details.

Similarly, Alberto described engaging in a recombinatory metaphoric process, arising from 'unintentionally looking at the structure of a glass building [external perceiving], I can't remember where, which then made me think that an ice-cube-looking carillon [recombinatory metaphoric process - cognitive/sensory/world domains] would look great being pulled by a truck [imaginative seeing]'. As these accounts show, both Ana and Alberto experienced recombinatory metaphoric processes while imagining a unique looking instrument (imaginative seeing). These 'unconnected matrices of experience' (Koestler, 1964, p. 48) that they retrieved, combined, and recontextualized in their minds to imaginatively see the LVSITANVS Carillon were rooted in their individual past experience and background, which become (unconscious) memory waiting to be activated. That is, Ana focused on mechanisms of existing carillons (her background is in engineering and music), whereas Alberto directed his attention, sometimes unconsciously, to buildings' structures, trucks, and unique designs (his background is in engineering and computer-aided design). Thus, experiencing and early creating intertwined, informing each other.

Meanwhile, we began discussing the carillon's sound: would it have a warm, full-bodied, or metallic timbre? Did we want a higher- or lower-pitch instrument? Would it be better to plan for a long- or short-sounding instrument? We reflected on our perceptions of the best-sounding carillons worldwide, thinking and imagining how to improve their sound. This mental (re)combination of specific sound characteristics from preferred instruments linked with reflections on our aesthetic reactions to them (recombinatory metaphoric process - cognitive/sensory/world domains), such that eventually we started hearing them as our future carillon (imaginative hearing); in Ana's words,

I listen to the sound of different carillons [external perceiving], thinking of what I like and what I don't like about them [thinking; internal perceiving], thinking of how they could be improved [while] combining and recombining various sound characteristics [recombinatory metaphoric process - cognitive/sensory/world domains], to come up with what I want [imaginative hearing]. And sometimes when you actually hear [the final product] you think, 'Darn it, this is even better than what I imagined!'

At this point in the process of imagining a unique sounding instrument, we were not concerned with the means needed to attain that sound (or whether it was attainable); we simply wanted to hear it in our minds as we imagined it would turn out in the future (imaginative hearing). Imaginatively sensing (seeing, hearing, touching) the different possibilities was critical for generating and 'living' alternative futures. 


\section{Reaching an impasse and gestating}

As entrepreneurs imagine novelty and think through the details of their creations, devising possible ways to attain them, they may encounter challenges that are not readily solvable, or an impasse. When they cannot easily overcome an impasse through conscious thought, entrepreneurs may resort to gestating - that is, letting solutions emerge from unconscious imagining. This process is analogous to the first phase of active imagination, a therapeutic technique developed by Jung (1997). Unconscious imagining is facilitated by metaphor-which provides 'the link between conscious experience and unconscious memory' (Modell, 2006, p. 25) - and rooted in a recombinatory metaphoric process akin to that explained in early creating. As part of gestating though, unconscious imagining is fundamentally involuntary and unconscious. Upon reaching an impasse, entrepreneurs can evoke solutions to challenges they cannot easily overcome through this unconscious process, but first, they need to develop a conscious intention to find a solution by turning attention toward the unconscious, using an active rather than passive process of imagining (Jung, 1997). Then, they must suspend conscious intention to let the unconscious generate solutions (Modell, 2006). This suspension of conscious intention is similar to creating a vacuum, as required by various forms of meditation that seek communication or unity with the self (Dyer, 2012). Jung (1997, p. 74) explains this unconscious process as $w u$ wei, or the Taoist idea of 'letting things happen'.

A strong intention toward a particular goal (e.g., overcoming a challenge) may be all that is necessary to trigger unconscious imagining, which then organizes memories and links previously uncombined experiences (Koestler, 1964). This unconscious recombinatory metaphoric process is facilitated by neurons firing and stimulating one another, even during sleep (Claxton, 1997; Modell, 2006). This unconscious process appears in Ana's description of her brain as drawers in an armoire, in which she does not 'know what happens inside when you close the drawers but then. . you come up with a new idea'. As this example affirms, early creating and reaching an impasse and gestating are not easily separated. They interconnect as entrepreneurs imagine novelty, consciously and unconsciously.

Another example involves an innovation related to ergonomics and responsiveness. The LVSITANVS Carillon's keyboard is highly ergonomic, and its mechanical system is among the most responsive worldwide. The final instrument thus met our high expectations, but the process to achieve these results featured many impasses. One challenge related to our attempt to integrate the American and European standards for carillon keyboards, according to their particular strengths and weaknesses. (Carillonists often complained of sliding down the bench, having to continually adjust their sitting position while performing on European instruments; this was not a problem on American keyboards, but these often caused back pain, particularly when the performer was used to playing on European instruments.) Accomplishing this task would let us create a keyboard on which carillonists could perform comfortably, with no need to adjust their sitting position and virtually no discomfort. We had a difficult time discerning how to overcome this integration challenge but also were determined to find a solution (developing conscious intention). Still, we often had to stop thinking about it and do something else (suspending conscious intention), like going for a walk, solving jigsaw puzzles, drinking espresso or a beer, or snacking. If none of these worked, we would stop for the day and go to sleep (allowing unconscious imagining to unfold). By no longer consciously thinking about the issue and letting our minds drift (suspending conscious intention) to topics unrelated to the project (allowing unconscious imagining to unfold), we eventually reached insights. Our attention would suddenly shift to an idea that unexpectedly popped into our minds, and we would excitedly rush back to our work station to resume tackling that specific challenge. Ana's quote illustrates how unconscious imagining unfolded for her: 
When I need to solve a problem with the carillon project [developing conscious intention], I eat, I even combine chocolate with chorizo to help with thinking and it helps me see things more clearly [thinking; imagining], not at that precise moment, but later.. . . Other times I consciously need to do something completely different.. ..For example, for figuring out the problem with the manualboard-pedalboard adjustment, the 'Aha!' moment [arose from] putting aside the problem [suspending conscious intention]; then, because I saw a little screw somewhere, that made me think [external perceiving; thinking]: 'Okay, maybe such a thing would work!' but at that time, I was doing something unrelated [yet allowing unconscious imagining to unfold].

Thus, unconscious imagining allows entrepreneurs to evoke solutions to problems by surfacing unconscious material (Jung, 1997). As insights surface though, they still need to be processed and interpreted, both inside and outside the mind (see next section). Even if entrepreneurs actively seek to bypass the reaching an impasse and gestating element, unconscious processes are inherently at the root of how they interact and relate with the world (Diamond, 2014).

\section{(Re)creating and evaluating imagined futures}

When entrepreneurs (re)create (i.e., continue re-working imagined futures that have yet to be refined or create completely new ones) and evaluate potential imagined futures and the courses of action associated with them, they actively process the unconscious material that surfaced while reaching an impasse and gestating or while generally interacting with the world. By actively processing unconscious material — a process that relates to the second phase of Jung's (1997) therapeutic active imagination technique - people might reach unexpected solutions to previously encountered impasses, which is often a joyful experience (Modell, 2006). Unconscious or raw material might comprise only vague images, emotions, impulses, or ideas that have yet to be interpreted (Jung, 1997). Reflecting the way the proposed model's elements inform one another, this notion emerged in the early creating element in Ana's explanation; while seeking inspiration in existing carillons and others' work, she developed an 'image in [her] mind [but it] isn't defined yet' until 'you start thinking about the details'.

The focus is not on the image per se but on what can be learned from reflecting on it (Sartre, 1978). To reflect on unconscious material (Jung, 1997) and devise solutions to problems (Arnheim, 2004), entrepreneurs use various expressive techniques (e.g., writing, drawing, prototyping) to give visible form to the raw images and ideas that surface from their unconscious. Some entrepreneurs prefer nonverbal techniques (e.g., sketching, prototyping); others opt to write down details first, followed by prototyping. Regardless, the goal is to continue developing ideas by interacting with non-discursive modalities (Boxenbaum, Jones, Meyer, \& Svejenova, 2018), such as material objects (raw materials, pen, paper), and thus spark and refine thoughts and images (Cornelissen, 2013). In the LVSITANVS Carillon project, ideas resulting from 'aha' moments were often broad and unclear (e.g., vague thought that changing the transmission system could improve responsiveness, faint image of a pedalboard combining American and European features, feeling that a problem could be resolved by re-thinking and re-imagining an issue that we previously assumed did not need further work). To hone our ideas, we sketched and wrote a lot (consciously processing unconscious material); although carillon specifications typically averaged five pages, a 53-page document thoroughly delineated all the specifications for our carillon. As a complement, conversations with others proved useful in continuing to hone ideas, as Alberto's quote illustrates:

When there are problems, sketching, drawing, and graphing are crucial to translate broad ideas into specific solutions [consciously processing unconscious material], but of course these need to be discussed 
with [Ana] because I need her opinion in music-related issues. Sometimes she'd say, 'Opá! Not that solution, otherwise the action will be too heavy for the musician!' Then, we'd continue working, ... . focusing on her sensory experience and conversations she had with [others who] developed carillons with which they weren't happy but didn't know why. We figured out why by talking and sketching appliedforce-vs.-deformation graphs by hand!

Throughout this process, we worked closely with a carillon manufacturer, which built a small prototype of the keys and their frame, helping us sharpen our thinking. While some ideas worked perfectly in theory and in our minds, as we gave them shape and put them into practice, crucial flaws were unveiled. Giving shape to raw ideas through material objects is important, because it allows entrepreneurs to create, refine, and evaluate different possibilities for the future, including the courses of action necessary to attain them. Entrepreneurs investigate means to attain a particular imagining but only entertain futures that truly appear possible, which Shackle (1979) calls 'epistemic possibility'. Many reasons may lead entrepreneurs to deem a future alternative possible, including available resources, embedded in particular institutional and business environments (Dolmans et al., 2014).

As we refined the details of the LVSITANVS Carillon and its supporting structure, we were unsure how many sponsors we would gather by the time we had to decide on an exact number of bells. Thus, we designed a structure - along with an ergonomic carillon keyboard and responsive transmission system - that would allow it to comprise up to 63 bells (even if it was inaugurated with only, say, 55 bells). Recognizing that we might be unable to reach that number of sponsored bells (money was a scarce resource: Portugal's economic environment was experiencing a major financial crisis), we started imagining and thinking through the details of different, smaller carillons (creating different imagined futures) and alternative means (e.g., sponsorship, transmission system, supporting structure materials) to attain them (formulating necessary courses of action). (We wanted the option to add bells after the inauguration, as funds became available, without risking structural collapse.) This highly complex process involved more than subtracting a certain number of bells; it required imagining different carillons (and various ways to accomplish them) that we deemed possible, because they made sense musically and acoustically (considering epistemic possibilities); Ana explained:

Before deciding, I imagine different carillons [creating different imagined futures] but for me, in my reality, carillon-one, carillon-two, and carillon-three are out of the question. I want carillon-four because I want the best and largest. . . . If you dream, dream big, it might come true or not, but you dreamt it. And if you reach for larger and get smaller first, if the option is there, you can get to larger later because these options are all possible [considering epistemic possibilities].

While creating different imagined futures, entrepreneurs may evaluate their viability and desirability by imagining themselves performing certain actions and reflecting on their reactions to them (Shackle, 1979). They may also engage empathic imaginations and 'vicariously experience the world as seen through the minds of others' (Modell, 2006, p. 115), such as evaluating the future that might be experienced by imagined end users (Chiles, Tuggle, McMullen, Bierman, \& Greening, 2010b). As we imagined different-sized carillons, their characteristics, and necessary courses of action, we experienced each possible instrument by imagining its sound, the touch of the manualboard and pedalboard, and the enjoyment or physical strain potentially attained during a performance (imaginative sensing). We also imaginatively visualized aesthetic (sensory, bodily, emotional) reactions to the different-sized carillons by future audience members and carillonists, evaluating each possible future by imaginatively placing ourselves in the shoes of both types of end user (empathic imagining). 
While evaluating imagined futures, entrepreneurs may engage in embodied imagining by transferring meaning across different sensory domains (Modell, 2006). During this metaphoric process, they pay special attention to sounds, visual images, sensations, and emotions emanating from within the body, as they are projected outward (Jung, 1997). Affective consciousness attained through reflection (Sartre, 1978) is essential to evaluating different imagined futures. While talking about her preferred carillon-four, Ana experienced a visible bodily reaction: 'Just talking about it, I'm getting goosebumps; it happens when I get excited thinking about it!' (embodied imagining). Alberto also explained that he felt driven to pursue a specific imagined future, despite financial and economic adversities, by 'a sign, within [him]self, from Mother Nature [embodied imagining] . . . that fuelled [his] stubbornness'. While (re)creating and evaluating imagined futures, entrepreneurs might viscerally experience a bad feeling about a possibility or prefer a particular imagined future due to some gut reaction. In this sense, Dyer (2012) suggests that how people feel often takes priority over what they know. But such feelings are not universal, and different entrepreneurs may develop distinct impressions of the same idea, because imagining, as an embodied process (Cornelissen, 2013), depends on the inner world, a unique past, and (un)conscious intentionality (Modell, 2006).

\section{Choosing and enterprising}

Choosing and enterprising marks the transition from ideation to actualization. While (re)creating and evaluating imagined futures, entrepreneurs formulate different imagined futures and necessary courses of action; then in the choosing and enterprising element, they choose which future to pursue and enterprise to create it. At its root, choosing requires embodied imagining, to evaluate imagined futures, so these two elements may occur simultaneously, especially for quick decisions arising from particular feelings. Feelings help entrepreneurs decide on and commit to an imagined future (Modell, 2006). Through emotional anticipation, they choose the imagined future that they believe will produce enjoyment; conversely, emotional anticipation of doubt does not lead to such a good state of mind, prompting entrepreneurs to pursue different imaginings (Shackle, 1979). Experiencing a good state of mind about a decision differs from rationally anticipating that a specific future and its corresponding course of action is feasible and attainable. Emotional anticipation moves beyond rational thought, by engaging and incorporating multiple layers of experience (e.g., emotional, cognitive, sensory).

The final decision for the LVSITANVS Carillon combined imagining and thinking through the details of each possible instrument, placing ourselves in others' shoes (empathic imagining), and pursuing good feelings (emotional anticipation) about a particular size, which affected the choice of bell foundry. For any musical instrument, each maker uses different manufacturing techniques that affect the final product's quality and price. Noting the estimated expenses to create the instrument and our envisioned budget, we had to choose between a larger carillon (with lower sound quality, because we would have to use a cheaper maker) or a much smaller carillon (with higher sound quality, because we could afford the high-end maker). These two options were obvious. But after considering possibilities for our future carillon, in terms of both rational feasibility and our feelings, we decided to acquire a top-of-the-line instrument, aiming for a high-quality, fairly large traveling carillon. The high-quality, small carillon made sense, rationally (and we considered several smaller carillons that we anticipated as feasible and attainable), but a carillon with fewer than 63 bells would not leave us in a good state of mind (Shackle, 1979) (emotional anticipation). As mentioned earlier, Ana imagined different carillons but only wanted carillon-four, the best and largest. Alberto had a gut feeling (embodied imagining) that we would find funding and 'that the LVSITANVS Carillon was going to happen'. Eventually, we were awarded a $€ 200,000$ grant that, along with a $€ 50,000$ first prize for innovative ideas in Portugal, a 
$€ 69,000$ loan, and sponsorship funds, gave us $€ 350,000$ to pay for a 63-bell traveling carillon, a flatbed semi-trailer, and a road truck.

After choosing which imagined future to pursue, entrepreneurs start enterprising, taking on the burden 'of accepting in advance the outcome whatever it may prove to be, and of accepting it while it is unknown' (Shackle, 1979, p. 139). Enterprising requires the use of resources, which are embedded in particular institutional and business environments (Dolmans et al., 2014), but due to limited resource availability, entrepreneurs must imagine their best uses. Ultimately, they commit to particular resource combinations, subjecting themselves to the risk of loss and uncertainty (Chiles et al., 2010a). As Ana expressed during the project's final stages:

We are now applying for governmental support, which will finance $75 \%$ and we need a loan on the other $25 \%$. We get the loan only if the project is approved; we lose everything if it isn't [subjecting oneself to loss . . . . It's $100 \%$ uncertainty because life is not a machine, you depend on people . . . and people are so subjective. If life were a machine, you could predict [the future] because you know the software that rules the machine. . . . Then, there's crises, crises, crises, and political colors . . . some parties are pro-culture, some others aren't . . . and all that keeps adding to the uncertainty, so you can't predict what's going to happen [subjecting oneself to uncertainty].

Enterprising also features passionately believing in a particular imagined future, in that it helps people persevere as they generate novelty (Dyer, 2012). Specifically, entrepreneurs may engage their mindsight (McGinn, 2006) to visualize a future that already exists in their minds, while passionately acting as if their novel idea were already manifested, living from a particular end, 'as if it had already materialized into the physical realm' (Dyer, 2012, p. 11). (In contrast, Gartner, Bird, and Starr, 1992, p. 17, describe entrepreneurs who talk and act "'as if" equivocal events were nonequivocal'.) When we decided to acquire the 63-bell traveling carillon (with a required flatbed semi-trailer and truck), we committed to being ready to perform several concerts on inauguration weekend (committing to a particular future). At times, during the final months of our project, we felt extreme stress and even discouragement. In retrospect though, passionately believing in the project was key in seeing it through to completion. In Ana's words, 'Without passion and without believing in it [without passionately believing], you simply don't do it because you have no will to go on, you just don't care.' For Alberto, 'If I didn't believe in [the project], it wouldn't have happened. I knew that it was going to happen but that it depended on us and our courageous will to fervidly continue fighting.' While enterprising to accomplish our imagined future, we visualized both a completely built carillon and its inaugural concerts (visualizing the imagined future), rehearsing our performances on other instruments as if we were already playing our carillon (acting ' $a$ s if'), so according to Ana,

Since the very beginning, it's 'as if'. . . . I don't have a carillon to play . . . [but] I play Renaissance songs in the organ that I want [to perform in] the carillon; so, [I'm] already doing work for the future [acting 'as if'] because then it's there already. . . . I see myself driving [the future traveling carillon], get into a place, disconnect the truck and start playing it! [visualizing the imagined future]. The future is true already, for me, it is an alternative reality.

Despite ongoing struggles (many of them related to economic challenges), the LVSITANVS Carillon was ultimately successful (about 2,000 people attended the inaugural concerts, which received extensive local and national news coverage). It gets driven around the country to perform concerts at various locations, and it receives visits from carillonists worldwide who want to see, listen, perform on, and learn about how we created the world's largest and one of the most innovative traveling carillons. Imagining was fundamental to seeing this project through to completion, 
and Ana and Alberto continually emphasized the importance of imagination for entrepreneuring. Notably, Alberto explained that 'entrepreneurship is the practice of dreams, and to imagine is to create from nothing, so without imagination there is no progress in entrepreneurship', and Ana stated, 'Imagination is the most important thing, if you don't imagine, how can you create?'

\section{Discussion}

This paper proposes a rhizomatic process model of entrepreneurial imagining, which we abductively generated from the situated performances of a team of arts entrepreneurs and imagination research reflecting various disciplinary perspectives. Through enactive research (Johannisson, 2011), we explored how a small team of Portuguese arts entrepreneurs created the world's largest traveling carillon. Arts entrepreneurs and artists are often trained to reflect on and verbalize creative processes, so this research context offers a meaningful opportunity to unpack the subtle processes of entrepreneurial imagining. With a radical processual approach (Hjorth et al., 2015), we generated our rhizomatic process model to conceptualize how entrepreneurs generate novelty and suggest five key elements: experiencing, early creating, reaching an impasse and gestating, (re) creating and evaluating imagined futures, and choosing and enterprising. We use the metaphor of the rhizome to deepen understanding of the heterogeneous, complex, interconnected, ever-changing, and indeterminate character of imagining (Chia, 1999). Specifically, we show that entrepreneurial imagining (1) is deeply entwined with perceiving and thinking; (2) involves partly ex nihilo creation; (3) comprises elements that interconnect, continually and iteratively informing one another; (4) unfolds in response to context; (5) entails a forward-looking perspective and an interplay among past, present, and future; (6) involves both conscious and unconscious processes; and (7) is an embodied and situated process requiring self-awareness and self-reflection. Thus, we respond to longstanding calls (e.g., Gartner, 2007; Sarasvathy, 2002) for attention to entrepreneurial imagining, by embracing qualitative inquiry as a generative lens for theorizing about the micro-foundations of entrepreneurial action (Dimov, 2011; Suddaby, Bruton, \& Si, 2015).

As a primary contribution, we theoretically detail entrepreneurial imagining as a complex, situated, relational performance that unfolds through conscious and unconscious, self-reflective and embodied processes. With our empirical account, we establish that imagining does not unfold in a vacuum but rather is deeply entwined with various bodily (e.g., sketching, processing affective reactions, giving shape to raw materials) and social (e.g., conversing with others, garnering stakeholder support, connecting with end users) activities. The rhizomatic formations, which are critical for entrepreneurial renewal, change, and transformation (Chia, 1999), develop within and are interconnected across an ecosystem of bodily and social interactions that affect and are affected by imagining. Generating novelty is a dance, grappling between boundless pursuits and contextual limitations; this includes struggling to breathe life into creations as a culmination of imaginings coming to fruition. Our model provides interdisciplinary insight into imagining, telling a story of the entrepreneurial journey that includes successes, hardships, and difficult choices. Shackle (1979) contributed concepts such as reports from the field, epistemic possibility, and a good state of mind, but his work does not explain all the concepts arising from our data. By integrating the seven books in our theoretical foundation with entrepreneurship and organization studies research, we gained critical insights into imagining, which we synthesized with Shackle's (1979) descriptions. Even if our model simplifies a dynamic, complex process, it tells an important story about imagination and choice by accounting for the myriad of imagined, forgone futures. The narratives that entrepreneurs typically tell emphasize triumphs, but entrepreneurs themselves may be scarred by the process of starting, failing, starting over, and repeating, all before attaining success. By 
embracing complexities and avoiding a linear entrepreneurial story, as sometimes appears in process models, our rhizomatic model captures insights into futures that never became.

This study has implications for both entrepreneurship and organization studies. First, our insights into entrepreneurial imagining add to organization studies, spotlighting how empirical interest in entrepreneurship can shed light on new ways of organizing (Hjorth et al., 2015). Specifically, entrepreneurial imagining can inform burgeoning efforts to explore non-discursive modalities in organization studies (Boxenbaum et al., 2018; Moser, Reinecke, den Hond, Svejenova, \& Croidieu, 2021). By being open to seeing, touching, tasting, and moving in organizational phenomena (Louisgrand \& Islam, 2021), researchers can theorize about various ways in which material, visual, and sensory stimuli inform organizational life. Yet up to this point, the primary focus has been on modes in-the-flesh, not modes in-the-mind or in-the-spirit, even though these different modes might inform one another. As our results detail, hearing can also be imagined, future vibrations can be felt before they manifest, and bodily reactions (self and others) can be anticipated. That is, intangible modalities are critical, including imaginative sensing, embodied imagining, and empathic imagining. Such activities, constructed in the mind through the power of imagining, deeply entangle with moving in physical spaces, touching tangible objects, and interacting with others, while oscillating between existing and fantasy worlds (Stanko, Dahm, Lahneman, \& Richter, 2020). Because entrepreneurs often engage their minds, in concert with their bodies and spirits, to imagine and actualize the new, entrepreneurship provides an especially rich context to explore the intangible dimensions of organizing within an already organized world.

Second, our model complements existing models of the broader entrepreneurial process, deepening insights into entrepreneurial imagining. Combining our model with constructivist models might illuminate how novel ideas emerge from (un)conscious processes, flow into entrepreneurs' actions and practices of bricolage, and eventually become both objectified and enacted. For example, in the first stage of Wood and McKinley's (2010) conceptual model of opportunity production, entrepreneurs first conceptualize and objectify an opportunity (overlapping with experiencing and early creating in our model) and ultimately enact it into a new venture (overlapping with choosing and enterprising in our model). Imagination also is important in Baker and Nelson's (2005) model of entrepreneurial bricolage, in that it enables the mental (re)combinations needed to build and leverage resource troves to support continuous creations of new offerings (overlapping with (re) creating and evaluating imagined futures in our model). Our work also complements models focused on key aspects of the entrepreneurial journey, providing a nuanced view of imagination as driving entrepreneurial action and the creation of artefacts (e.g., ventures, markets, capabilities). Notably, in the first level of Selden and Fletcher's (2015) model (entrepreneur sense-making subsystem), entrepreneurs engage in self-reflexivity to recursively evaluate and exploit contingent experience while bridging it with the pursuit of imagined, uncertain futures (overlapping with experiencing, early creating, and (re)creating and evaluating imagined futures in our model). Relative to Dimov's (2016), our model overlaps mostly with the operational/technical feasibility meta-category, expanding understanding of how imagining can fuel the development of unique products that match the operational and technical preferences of specific customers, existing and imagined. Overall, our study's detailed empirical account exemplifies a means to deepen extant literature; we encourage researchers to continue generating rich, in-depth qualitative data to improve this rhizomatic model, through extensions and ongoing modifications.

Third, our radical processual positioning creates insights for research taking a radical Austrian perspective, which emphasizes processual approaches, ex nihilo creation, and contextualism (Chiles et al., 2010a). Specifically, with our rhizomatic model, scholars can explore partly ex nihilo creation more fully, as a process that emerges from the actions of imaginative, complex human beings embedded within uncertain, dynamic, messy contexts (Hjorth, 2013; Shackle, 1979). 
Radical Austrian scholarship has provided insights into the critical role of entrepreneurs' forwardlooking imaginations (e.g., Chiles et al., 2010b), but more work is needed to specify the processes involved in entrepreneurial imagining and their connection to entrepreneuring. Combining our model with other radical Austrian insights (beyond Shackle, 1979), such as institutional, capital, and market process theories, may enable further progress toward understanding the emergence of order in nonequilibrium, the connection between entrepreneuring and the creation of value (economic and non-economic), and the ways in which market processes and institutional environments influence and are influenced by entrepreneurs' subjective imaginations.

Fourth, our investigation of the performances of a team of arts entrepreneurs adds to the nascent, much-needed conversation between organization studies and art (Hjorth et al., 2018; Holm \& Beyes, 2021). Artists everywhere engage in entrepreneurial practices, for various reasons (e.g., survival, following a passion), and skillfully give shape to novelty through their art (Scherdin \& Zander, 2011). The entrepreneurial and organizational aspects of artistic practices tend to be overlooked, particularly in mainstream research (Elias et al., 2018). But as an especially rich context for exploring creative processes, arts entrepreneuring can help scholars gain an in-depth, holistic understanding of how entrepreneuring and organizing unfold over time, out of entrepreneurs' imaginative acts, for both economic and non-economic purposes. We intentionally broadened the scope beyond a mainstream entrepreneurship focus on rationality to explore how resilience and passionate belief drive arts entrepreneurs to disrupt dominant, organized contexts. As this case shows, stubbornness, desire, and even foolishness are powerful forces in making a difference for the future (Hjorth, 2014). We encourage further work at the intersection of organization studies and art, to explore how entrepreneuring and organizing also unfold through processes of transformation (Scherdin \& Zander 2011), aesthetic collaboration (Louisgrand \& Islam, 2021), and artful play (Hjorth et al., 2018).

Some limitations suggest other directions for research. Notably, our theoretical foundation is a select set of texts that provide interdisciplinary insights into imagining but certainly do not represent an all-inclusive literature review. Researchers could draw additional insights from other disciplines (e.g., sociology, music psychology) to incorporate concepts not taken into account in our model. That is, scholars could use our proposed model reflexively to explore entrepreneurial imagining further. The model also includes the relationship between entrepreneurs and their surrounding environment, but its focus is on individual imaginative acts. This necessary first step reveals how novelty gets generated, but as our data show, entrepreneurial imagining often is a collective process. Continued research thus might explore collective dimensions of entrepreneurial imagining, building from collective memory and futuristic fantasies (Foroughi, Coraiola, Rintamäki, Mena, \& Foster, 2020) or collective imagination as a means to radically re-imagine organizing (Komporozos-Athanasiou \& Fotaki, 2015).

In closing, despite its central role in entrepreneurial and organizational life, imagining is an understudied topic. To begin addressing this oversight, we propose a rhizomatic process model of entrepreneurial imagining that might provide entrepreneurship and organization studies scholars with a foundation to advance research. Our process model can guide efforts toward improved understanding of how entrepreneurs engage their forward-looking imaginations, which materialize in their everyday performances, to generate novelty and make a difference in the world. We hope this model paves the way for researchers to explore, in greater depth, how imagining unfolds as an essential part of entrepreneuring and organizing.

\section{Acknowledgements}

We thank our research participants Ana Elias and Alberto Elias for their inventive imaginings. This article is dedicated to them and to Maria Celeste Traquina, who tirelessly works behind the scenes of this study's arts 
venture. We also appreciate the insightful comments provided on earlier drafts by Michael Diamond, Dan Greening, and Chris Robert, as well as the participants of the $6^{\text {th }}$ Biennial Qualitative Research in Management and Organization Conference and the $3^{\text {rd }}$ Annual Entrepreneurship as Practice Conference. Lastly, we are sincerely grateful to our Editors Daniel Hjorth and Trish Reay, as well as three incredibly constructive reviewers, for their encouragement and thoughtful guidance throughout the review process.

\section{Funding}

The authors acknowledge financial support from the University of Missouri's Robert J. Trulaske, Sr. College of Business.

\section{ORCID iDs}

Sara R. S. T. A. Elias (iD https://orcid.org/0000-0001-7548-3113

Brett Crawford iD https://orcid.org/0000-0001-7170-1611

\section{References}

Alvesson, Mats, \& Sköldberg, Kaj (2009). Reflexive methodology. London: SAGE Publications.

Arnheim, Rudolf (2004). Visual thinking (2nd edition). Berkeley, CA: University of California Press.

Augustine, Sharon (2014). Living in a post-coding world: Analysis as assemblage. Qualitative Inquiry, 20, $747-753$.

Baker, Ted, \& Nelson, Reed (2005). Creating something from nothing: Resource construction through entrepreneurial bricolage. Administrative Science Quarterly, 50, 329-366.

Boxenbaum, Eva, Jones, Candace, Meyer, Renate, \& Svejenova, Silviya (2018). Towards an articulation of the material and visual turn in organization studies. Organization Studies, 39, 597-616.

Brinkmann, Svend, \& Kvale, Steinar (2015). InterViews (3rd edition). Thousand Oaks, CA: SAGE Publications.

Chia, Robert (1999). A 'rhizomic' model of organizational change and transformation: Perspective from a metaphysics of change. British Journal of Management, 10, 209-227.

Chiles, Todd, Bluedorn, Allen, \& Gupta, Vishal (2007). Beyond creative destruction and entrepreneurial discovery: A radical Austrian approach to entrepreneurship. Organization Studies, 28, 467-493.

Chiles, Todd, Vultee, Denise, Gupta, Vishal, Greening, Daniel, \& Tuggle, Christopher (2010a). The philosophical foundations of a radical Austrian approach to entrepreneurship. Journal of Management Inquiry, 19, 138-164.

Chiles, Todd, Tuggle, Christopher, McMullen, Jeffery, Bierman, Leonard, \& Greening, Daniel (2010b). Dynamic creation: Extending the radical Austrian approach to entrepreneurship. Organization Studies, $31,7-46$.

Claxton, Guy (1997). Hare brain, tortoise mind. Hopewell, NJ: Ecco.

Cope, Jason (2005). Researching entrepreneurship through phenomenological inquiry. International Small Business Journal, 23, 163-189.

Cornelissen, Joep (2013). Portrait of an entrepreneur: Vincent van Gogh, Steve Jobs, and the entrepreneurial imagination. Academy of Management Review, 38, 700-709.

Cornelissen, Joep, \& Clarke, Jean (2010). Imagining and rationalizing opportunities: Inductive reasoning and the creation and justification of new ventures. Academy of Management Review, 35, 539-557.

Crawford, Brett, \& Dacin, Tina (2020). Policing work: Emotions and violence in institutional work. Organization Studies. https://doi.org/10.1177/0170840620941614

Creed, Douglas, Taylor, Steven, \& Hudson, Bryant (2020). Institutional aesthetics: Embodied ways of encountering, evaluating, and enacting institutions. Organization Studies, 41, 415-435.

Cunliffe, Ann, \& Eriksen, Matthew (2011). Relational leadership. Human Relations, 64, 1425-1449.

Davidsson, Per (2004). Researching entrepreneurship. New York: Springer.

Deleuze, Gilles, \& Guattari, Félix (1987). A thousand plateaus (Brian Massumi, Trans.). Minneapolis: University of Minnesota. 
Diamond, Michael (2014). Metaphoric processes and organizational change: A contemporary psychoanalytic perspective. Organisational \& Social Dynamics, 14, 104-129.

Dimov, Dimo (2011). Grappling with the unbearable elusiveness of entrepreneurial opportunities. Entrepreneurship Theory and Practice, 35, 57-81.

Dimov, Dimo (2016). Towards a design science of entrepreneurship. In Jerome Katz \& Andrew Corbett (Eds.), Advances in entrepreneurship, firm emergence and growth, Vol. 18 (pp. 1-31). Bingley, UK: Emerald Group.

Dolmans, Sharon, van Burg, Elco, Reymen, Isabelle, \& Romme, Georges (2014). Dynamics of resource slack and constraints: Resource positions in action. Organization Studies, 35, 511-549.

Dyer, Wayne (2012). Wishes fulfilled. London: Hay House.

Elias, Sara R.S.T.A., Chiles, Todd, Duncan, Carrie, \& Vultee, Denise (2018). The aesthetics of entrepreneurship: How arts entrepreneurs and their customers co-create aesthetic value. Organization Studies, 39, 345-372.

Fletcher, Denise (2011). A curiosity for contexts: Entrepreneurship, enactive research and autoethnography. Entrepreneurship \& Regional Development, 23, 65-76.

Foroughi, Hamid, Coraiola, Diego, Rintamäki, Jukka, Mena, Sébastien, \& Foster, William (2020). Organizational memory studies. Organization Studies, 41, 1725-1748.

Gartner, William (2007). Entrepreneurial narrative and a science of the imagination. Journal of Business Venturing, 22, 613-627.

Gartner, William, Bird, Barbara, \& Starr, Jennifer (1992). Acting as if: Differentiating entrepreneurial from organizational behavior. Entrepreneurship Theory and Practice, 16, 13-31.

Hindle, Kevin (2010). Skillful dreaming. Entrepreneurial Narrative: Theory, Ethnomethodology and Reflexivity, 1, 101-139.

Hjorth, Daniel (2013). Absolutely fabulous! Fabulation and organization-creation in processes of becomingentrepreneur. Society and Business Review, 8, 205-224.

Hjorth, Daniel (2014). Entrepreneuring as organisation-creation. In Rolf Sternberg \& Gerhard Krauss (Eds.), Handbook of research on entrepreneurship and creativity (pp. 97-121). Cheltenham, UK: Edward Elgar.

Hjorth, Daniel, Holt, Robin, \& Steyaert, Chris (2015). Entrepreneurship and process studies. International Small Business Journal, 33, 599-611.

Hjorth, Daniel, Strati, Antonio, Drakopoulou Dodd, Sarah, \& Weik, Elke (2018). Organizational creativity, play and entrepreneurship: Introduction and framing. Organization Studies, 39, 155-168.

Holm, Ditte, \& Beyes, Timon (2021). How art becomes organization: Reimagining aesthetics, sites and politics of entrepreneurship. Organization Studies. https://doi.org/10.1177/0170840621998571

Johannisson, Bengt (2011). Towards a practice theory of entrepreneuring. Small Business Economics, 36, $135-150$.

Jung, Carl (1997). Jung on active imagination. Chodorow, Joan (Ed.). Princeton, NJ: Princeton University.

Kier, Alexander, \& McMullen, Jeffery (2018). Entrepreneurial imaginativeness in new venture ideation. Academy of Management Journal, 61, 2265-2295.

Koestler, Arthur (1964). The act of creation. New York: Macmillan.

Komporozos-Athanasiou, Aris, \& Fotaki, Marianna (2015). A theory of imagination for organization studies using the work of Cornelius Castoriadis. Organization Studies, 36, 321-342.

Lachmann, Ludwig (1986). The market as an economic process. New York: Basil Blackwell.

Louisgrand, Nathalie, \& Islam, Gazi (2021). Tasting the difference: A relational-epistemic approach to aesthetic collaboration in haute cuisine. Organization Studies, 42, 269-300.

Lounsbury, Michael, Gehman, Joel, \& Glynn, Mary Ann (2019). Beyond homo entrepreneurus: Judgment and the theory of cultural entrepreneurship. Journal of Management Studies, 56, 1214-1236.

McGinn, Colin (2006). Mindsight. Cambridge, MA: Harvard University Press.

McMullen, Jeffery, \& Dimov, Dimo (2013). Time and the entrepreneurial journey: The problems and promise of studying entrepreneurship as a process. Journal of Management Studies, 50, 1481-1512.

Modell, Arnold (2006). Imagination and the meaningful brain. Cambridge, MA: MIT Press.

Moroz, Peter, \& Hindle, Kevin (2012). Entrepreneurship as a process: Toward harmonizing multiple perspectives. Entrepreneurship Theory and Practice, 36, 781-818. 
Moser, Christine, Reinecke, Juliane, den Hond, Frank, Svejenova, Silviya, \& Croidieu, Grégoire (2021). Biomateriality and organizing: Towards an organizational perspective on food. Organization Studies, 42, 175-193.

Nicolini, Davide (2009). Zooming in and zooming out. In Sierk Ybema, Dvora Yanow, Harry Wels, \& Frans Kamsteeg (Eds.), Organizational ethnography (pp. 120-138). London: SAGE Publications.

Owen, William (1984). Interpretive themes in relational communication. Quarterly Journal of Speech, 70 , 274-287.

Parkkari, Piritta, \& Verduijn, Karen (2019). Introducing three academic conversations. In Eddy Laveren, Robert Blackburn, Ulla Hytti, \& Hans Landström (Eds.), Rigour and relevance in entrepreneurship research, resources and outcomes (pp. 29-47). Cheltenham, UK: Edward Elgar.

Rindova, Violina, Barry, Daved, \& Ketchen, David (2009). Entrepreneuring as emancipation. Academy of Management Review, 34, 477-491.

Sarasvathy, Saras (2001). Causation and effectuation: Toward a theoretical shift from economic inevitability to entrepreneurial contingency. Academy of Management Review, 26, 243-263.

Sarasvathy, Saras (2002). Entrepreneurship as economics with imagination. Business Ethics Quarterly: The Ruffin Series, 3, 95-112.

Sartre, Jean-Paul (1978). The psychology of imagination. Westport, CT: Greenwood.

Scherdin, Mikael, \& Zander, Ivo (2011). Art entrepreneurship. In Mikael Scherdin \& Ivo Zander (Eds.), Art entrepreneurship (pp. 1-9). Cheltenham, UK: Edward Elgar.

Schumpeter, Joseph (1939). Business cycles, Vol. 1. New York: McGraw-Hill.

Selden, Paul, \& Fletcher, Denise (2015). The entrepreneurial journey as an emergent hierarchical system of artifact-creating processes. Journal of Business Venturing, 30, 603-615.

Shackle, George (1979). Imagination and the nature of choice. Edinburgh: Edinburgh University Press.

St. Pierre, Elizabeth, \& Jackson, Alecia (2014). Qualitative data analysis after coding. Qualitative Inquiry, $20,715-719$.

Stake, Robert (1995). The art of case study research. Thousand Oaks, CA: SAGE Publications.

Stanko, Taryn, Dahm, Patricia, Lahneman, Brooke, \& Richter, Jonathon (2020). Navigating an identity playground: Using sociomateriality to build a theory of identity play. Organization Studies. https://doi. org/10.1177/0170840620944542

Steyaert, Chris (1997). A qualitative methodology for process studies of entrepreneurship. International Studies of Management \& Organization, 27, 13-33.

Suddaby, Roy, Bruton, Garry, \& Si, Steven (2015). Entrepreneurship through a qualitative lens: Insights on the construction and/or discovery of entrepreneurial opportunity. Journal of Business Venturing, 30, $1-10$.

Thompson, Neil (2018a). Imagination and creativity in organizations. Organization Studies, 39, 229-250.

Thompson, Neil (2018b). Critiquing and renewing the entrepreneurial imagination. In Alain Fayolle, Stratos Ramoglou, Mine Karatas-Ozkan, \& Katerina Nicolopoulou (Eds.), Philosophical reflexivity and entrepreneurship research (pp. 126-138). London: Routledge.

Wood, Matthew, \& McKinley, William (2010). The production of entrepreneurial opportunity: A constructivist perspective. Strategic Entrepreneurship Journal, 4, 66-84.

\section{Author biographies}

Sara R. S. T. A. Elias is an assistant professor of entrepreneurship at the University of Victoria's Gustavson School of Business and a research associate of the Center for Psychosocial Organization Studies. Her research interests include creative entrepreneurial processes, entrepreneurial imagining, arts entrepreneurship, aesthetics in organizations and entrepreneurship, entrepreneurship as practice, and qualitative methodologies. She has published in Organization Studies, Organization Theory, Organization, Journal of Management Inquiry, and Organizational Research Methods, among others.

Todd H. Chiles is a senior research fellow at the Center for the Study of Complexity, Creation, and Change and an emeritus professor at the University of Missouri's Trulaske College of Business. His research explores entrepreneurship as a complex creative process, featuring processes involving emergence, imagination, and 
far-from-equilibrium dynamics, and has been published in journals such as Academy of Management Review, Organization Studies, Journal of Management Studies, and Organization Science.

Brett Crawford is an assistant professor of management at the Seidman College of Business at Grand Valley State University. His research explores how organizations shape social and institutional meaning over time. Brett earned his PhD from Copenhagen Business School. He has published in Organization Studies, Organization Theory, Journal of Management Inquiry, and Strategic Organization, among others. 